\title{
Changing sources and environmental factors reduce the rates of decline of organochlorine pesticides in the Arctic atmosphere
}

\author{
S. Becker ${ }^{1}$, C. J. Halsall ${ }^{1}$, W. Tych ${ }^{1}$, R. Kallenborn ${ }^{2,3}$, M. Schlabach ${ }^{2}$, and S. Man $\emptyset^{2}$ \\ ${ }^{1}$ Lancaster Environment Centre, Lancaster University, Lancaster LA1 4YQ, UK \\ ${ }^{2}$ Norwegian Institute for Air Research (NILU), P.O. Box 100, 2007 Kjeller, Norway \\ ${ }^{3}$ The Norwegian University of Life Sciences (UMB), Department of Chemistry, Biotechnology and Food Scienc, P.O. Box \\ 5003, 1432 Aas, Norway \\ Correspondence to: C. Halsall (c.halsall@lancaster.ac.uk)
}

Received: 15 October 2008 - Published in Atmos. Chem. Phys. Discuss.: 8 January 2009

Revised: 28 March 2012 - Accepted: 13 April 2012 - Published: 8 May 2012

\begin{abstract}
An extensive database of organochlorine (OC) pesticide concentrations measured at the Norwegian Arctic monitoring station at Ny-Ålesund, Svalbard, was analysed to assess longer-term trends in the Arctic atmosphere. Dynamic Harmonic Regression (DHR) is employed to investigate the seasonal and cyclical behaviour of chlordanes, DDTs and hexachlorobenzene (HCB), and to isolate underlying interannual trends. Although a simple comparison of annual mean concentrations (1994-2005) suggest a decline for all of the OCs investigated, the longer-term trends identified by DHR only show a significant decline for $p, p^{\prime}$-DDT. Indeed, HCB shows an increase from 2003-2005. This is thought to be due to changes in source types and the presence of impurities in current use pesticides, together with retreating sea ice affecting air-water exchange. Changes in source types were revealed by using isomeric ratios for the chlordanes and DDTs. Declining trends in ratios of trans-chlordane/cischlordane $(\mathrm{TC} / \mathrm{CC})$ indicate a shift from primary sources, to more "weathered" secondary sources, whereas an increasing trend in $o, p^{\prime}$-DDT/ $p, p^{\prime}$-DDT ratios indicate a shift from use of technical DDT to dicofol. Continued monitoring of these OC pesticides is required to fully understand the influence of a changing climate on the behaviour and environmental cycling of these chemicals in the Arctic as well as possible impacts from "new" sources.
\end{abstract}

\section{Introduction}

The use of organochlorine (OC) pesticides has been subject to restrictions in the majority of the world for many years now due to their persistence in the environment and their ability to cause harm. OC pesticides are of particular relevance as they are semi-volatile and prone to longrange atmospheric transport (LRAT), thus affecting areas far removed from the initial point of release (UNECE, 1998). As such they have been the subject of long term monitoring campaigns initiated by the Arctic Environment Protection Strategy (AEPS), which was signed in June 1991 by circumpolar countries to help protect the Arctic. Air monitoring in several circumpolar countries (including Canada, Norway and Russia) falls under the auspices of the Arctic Monitoring Assessment Programme (AMAP, 2002). Concern over chemicals like the OC pesticides in the Arctic can be illustrated by considering human exposure to these compounds. For example, a study of chlordane exposure to an Inuit population living on Broughton Island, Canada. in the late-1990s estimated a daily intake of $\sim 5 \mu \mathrm{g} \mathrm{kg}^{-1} \mathrm{bw} \mathrm{day}^{-1}$, whereas North Americans (where chlordane use was high), were exposed to $\sim 0.1 \mu \mathrm{g} \mathrm{kg}^{-1}$ bw day ${ }^{-1}$ (van Oostdam et al., 2005; Dougherty et al., 2000). To date, there have been several publications investigating the temporal and spatial trends of OC pesticides, although these have mainly focused on the Canadian Arctic (e.g. Hung et al. 2002, 2005), or over much shorter time-series (e.g. Oehme et al., 1995; Berg et al., 2004). Therefore, this paper investigates the temporal trends of selected OC pesticides in the atmosphere of 
the Norwegian Arctic utilising data collected by the Norwegian Air Research Institute (NILU) at Ny-Ålesund, Svalbard for the period 1994-2005. The following OC pesticide datasets: chlordanes (trans- and cis- isomers), DDTs, and hexachlorobenzene (HCB) were analysed with the use of dynamic harmonic regression (DHR), a sophisticated timeseries modelling tool, to determine the seasonal behaviour and long-term temporal trends of these compounds. For ease of reading, these chemicals are considered separately throughout the paper.

Chlordane - Chlordane was used extensively on food and non-food agricultural crops, residential lawns and gardens, and in buildings for the control of structural pests such as termites. The use of this pesticide was banned in the majority of the world in the late 1980s, with use remaining high in areas such as California until 1988, when a ban was introduced in the US (Shigenaka, 1990; Connor et al., 2006). Chlordane is a mixture of different chlordane isomers, other chlorinated hydrocarbons and several other components. The two main constituents in the technical mixture are transchlordane (TC) and cis-chlordane (CC), and both are reported in the Norwegian air dataset. Ratios of these two isomers can be used to indicate recent or ongoing use of the technical mixture as opposed to re-volatilisation from soils arising from historical use (Bidleman and Leone, 2004). The ratio of these compounds (TC/CC) found in the technical mixture used in the US is $\sim 1.16$ (Jantunen et al., 2000), although global ratios in technical chlordane have been seen to range from 1.26-1.35 TC/CC (Patton et al., 1991). A recent investigation by Hung et al. (2005) found that, although there were occasional spikes in TC/CC ratios observed at Alert between 1995-1997, these were usually related to high episodes of heptachlor, suggesting use of heptachlor containing TC and CC at these times. Generally, a ratio of $<1$ in the atmosphere indicates an older source i.e. historical use and depletion of TC, whereas a ratio $>1$ indicates recent use of this pesticide. The average ratio in the early 2000s observed in the Arctic atmosphere was $<1$, suggesting that secondary sources from soils and vegetation are now the predominant contemporary sources to influence the Arctic (Bidleman et al., 2002).

DDTs - The use of DDT in its technical form was widely banned in the 1970s, but it is still permitted for use in some countries under special licence. For example, this chemical is still used in technical form for the control of disease vectors in countries such as Africa and South America and in anti-fouling paints in China (Li et al., 2007). Technical grade DDT is made up of $\geq 80 \% p, p^{\prime}$-DDT; $\geq 15 \% o, p^{\prime}$-DDT and smaller quantities of $p, p^{\prime}$ - and $o, p^{\prime}$-DDD. DDT is also used in the production of dicofol which is used to kill mites such as the red spider mite on crops (PAN, 2008). From 1988-2000, the annual production of DDT in China was estimated to be $\sim 6000 \mathrm{t}$, of which $\sim 80 \%$ was used for the production of dicofol (Yang et al., 2007). DDT and chlorinated DDT (Cl-DDT) may remain as impurities after the synthe- sis reactions involved in the production of dicofol (Zhang et al., 2002; Qiu et al., 2005; Li et al., 2006). The $p, p^{\prime}$ - and $o, p^{\prime}$ - isomers of DDT, DDE and DDD are investigated here in order to assess temporal trends and changing source types. Ratios can be used to give an idea of the age of the source of DDT by taking a ratio of DDT/DDE + DDD, and whether the signal is from the use of Technical DDT or dicofol by taking a ratio of $o, p^{\prime}$-DDT $/ p, p^{\prime}$-DDT.

Hexachlorobenzene $(H C B)$ - HCB has had several uses in industry and agriculture, as a porosity control agent, a fungicide and as a wood preserving agent. Bans or restrictions on use were implemented throughout the period 19602000, with the latest recorded ban being introduced in 2003 in Canada. The use of HCB as an intermediate (mainly for chemicals used in pyrotechnics) occurs in China and Russia (Xu et al., 2004; Barber et al., 2005). Global HCB emissions from all emission types have been estimated at between $12000-92000 \mathrm{~kg} \mathrm{yr}^{-1}$ based on information from the mid 1990s (Bailey, 2001).

\section{Methods}

\subsection{Air monitoring database}

Atmospheric samples were collected weekly over a period of $48 \mathrm{~h}$ at $\mathrm{Ny}$-Ålesund, Svalbard, Norway $\left(78^{\circ} 55^{\prime} \mathrm{N} / 11^{\circ} 56^{\prime} \mathrm{E}\right)$. The database extends back to 1993; however as air samples were not taken systematically throughout 1993, this year has been excluded from the data analysis. Details of air concentrations for this period can be found in an earlier publication by Oehme et al. (1996). The systematic analysis of the DDTs did not begin until 1994, although these were measured during shorter sampling campaigns prior to this.

Details of sampling and analysis can be found in previous publications (Oehme et al., 1995, 1996). Briefly, each sample was collected using a High-Volume sampler aspirating $1000-1100 \mathrm{~m}^{3}$ of air, at a rate of $\sim 20 \mathrm{~m}^{3} \mathrm{~h}^{-1}$ with the particulate and vapour phases operationally collected on a glass fibre filter (GFF), and two sequential polyurethane foam (PUF) plugs, respectively. As a quality control procedure, prior to sample extraction, the first PUF was spiked with $50 \mathrm{ng}$ of $\varepsilon-\mathrm{HCH}$ to test for analyte recovery. The GFF and PUFs were then extracted separately for $8 \mathrm{~h}$ with $n$-hexane/diethyl ether (9:1). The extracts were then combined (since only a small fraction of the compounds analysed $(<10 \%)$ are found in the particulate phase) and exchanged to $100 \mu \mathrm{L} n$-nonane keeper solvent. The resulting extract was then subject to acid clean-up (concentrated sulphuric acid) and column chromatography (silica column). Following the addition of octachloronapthalene as an internal standard, the samples were reduced to $\sim 100 \mu \mathrm{L}$ and the OC pesticides qualified/quantified using GC-MS (operating in NCI mode). Instrumental operating conditions can be found in Oehme et al. $(1995,1996)$. The resulting POPs database is maintained 
Table 1. Annual arithmetic means in $\mathrm{pg} \mathrm{m}^{-3}$ (standard deviation) for trans-chlordane (TC) and cis-chlordane (CC), DDT (individual compounds and total DDT) and HCB measured at Zeppelin, Svalbard, Norway 1994-2005. The average summer (June-August) and winter (January-March) ratios of TC/CC are also given.

\begin{tabular}{|c|c|c|c|c|c|c|c|c|c|c|c|c|}
\hline & 1994 & 1995 & 1996 & 1997 & 1998 & 1999 & 2000 & 2001 & 2002 & 2003 & 2004 & 2005 \\
\hline trans-chlordane & $\begin{array}{l}0.70 \\
(0.57)\end{array}$ & $\begin{array}{l}0.42 \\
(0.24)\end{array}$ & $\begin{array}{l}0.59 \\
(0.40)\end{array}$ & $\begin{array}{l}0.54 \\
(0.28)\end{array}$ & $\begin{array}{l}0.37 \\
(0.20)\end{array}$ & $\begin{array}{l}0.36 \\
(0.19)\end{array}$ & $\begin{array}{l}0.26 \\
(0.13)\end{array}$ & $\begin{array}{l}0.34 \\
(0.20)\end{array}$ & $\begin{array}{l}0.37 \\
(0.25)\end{array}$ & $\begin{array}{l}0.26 \\
(0.14)\end{array}$ & $\begin{array}{l}0.25 \\
(0.15)\end{array}$ & $\begin{array}{l}0.25 \\
(0.13)\end{array}$ \\
\hline cis-chlordane & $\begin{array}{l}1.20 \\
(0.41)\end{array}$ & $\begin{array}{l}0.96 \\
(0.30)\end{array}$ & $\begin{array}{l}1.17 \\
(0.50)\end{array}$ & $\begin{array}{l}0.81 \\
(0.45)\end{array}$ & $\begin{array}{l}0.78 \\
(0.35)\end{array}$ & $\begin{array}{l}0.78 \\
(0.19)\end{array}$ & $\begin{array}{l}0.65 \\
(0.15)\end{array}$ & $\begin{array}{l}0.85 \\
(0.29)\end{array}$ & $\begin{array}{l}0.84 \\
(0.21)\end{array}$ & $\begin{array}{l}0.69 \\
(0.20)\end{array}$ & $\begin{array}{l}0.67 \\
(0.14)\end{array}$ & $\begin{array}{l}0.61 \\
(0.13)\end{array}$ \\
\hline $\mathrm{TC} / \mathrm{CC}$ summer & 0.39 & 0.26 & 0.34 & 0.58 & 0.12 & 0.28 & 0.19 & 1.49 & 0.21 & 0.22 & 0.21 & 0.23 \\
\hline TC/CC winter & 0.88 & 0.69 & 0.68 & 0.74 & 0.70 & 0.64 & 0.62 & 1.03 & 0.76 & 0.59 & 0.59 & 0.64 \\
\hline$p, p^{\prime}$-DDT & $\begin{array}{l}0.87 \\
(0.60)\end{array}$ & $\begin{array}{l}0.32 \\
(0.25)\end{array}$ & $\begin{array}{l}0.38 \\
(0.22)\end{array}$ & $\begin{array}{l}0.26 \\
(0.27)\end{array}$ & $\begin{array}{l}0.55 \\
(0.51)\end{array}$ & $\begin{array}{l}0.57 \\
(0.56)\end{array}$ & $\begin{array}{l}0.14 \\
(0.06)\end{array}$ & $\begin{array}{l}0.14 \\
(0.13)\end{array}$ & $\begin{array}{l}0.14 \\
(0.15)\end{array}$ & $\begin{array}{l}0.14 \\
(0.11)\end{array}$ & $\begin{array}{l}0.10 \\
(0.07)\end{array}$ & $\begin{array}{l}0.09 \\
(0.08)\end{array}$ \\
\hline$o, p^{\prime}$-DDT & $\begin{array}{l}1.04 \\
(0.75)\end{array}$ & $\begin{array}{l}0.50 \\
(0.44)\end{array}$ & $\begin{array}{l}0.48 \\
(0.28)\end{array}$ & $\begin{array}{l}0.39 \\
(0.27)\end{array}$ & $\begin{array}{l}0.51 \\
(0.28)\end{array}$ & $\begin{array}{l}0.47 \\
(0.34)\end{array}$ & $\begin{array}{l}0.24 \\
(0.14)\end{array}$ & $\begin{array}{l}0.26 \\
(0.24)\end{array}$ & $\begin{array}{l}0.26 \\
(0.20)\end{array}$ & $\begin{array}{l}0.22 \\
(0.14)\end{array}$ & $\begin{array}{l}0.55 \\
(0.34)\end{array}$ & $\begin{array}{l}0.19 \\
(0.14)\end{array}$ \\
\hline$p, p^{\prime}-\mathrm{DDE}$ & $\begin{array}{l}1.93 \\
(1.52)\end{array}$ & $\begin{array}{l}0.87 \\
(0.80)\end{array}$ & $\begin{array}{l}1.50 \\
(2.03)\end{array}$ & $\begin{array}{l}1.15 \\
(1.67)\end{array}$ & $\begin{array}{l}1.13 \\
(0.55)\end{array}$ & $\begin{array}{l}0.98 \\
(1.43)\end{array}$ & $\begin{array}{l}0.47 \\
(0.36)\end{array}$ & $\begin{array}{l}0.81 \\
(1.04)\end{array}$ & $\begin{array}{l}0.98 \\
(2.32)\end{array}$ & $\begin{array}{l}0.86 \\
(0.80)\end{array}$ & $\begin{array}{l}2.32 \\
(10.74)\end{array}$ & $\begin{array}{l}0.09 \\
(0.08)\end{array}$ \\
\hline$o, p^{\prime}-\mathrm{DDE}$ & $\begin{array}{l}1.42 \\
(1.04)\end{array}$ & $\begin{array}{l}0.22 \\
(0.23)\end{array}$ & $\begin{array}{l}0.16 \\
(0.14)\end{array}$ & $\begin{array}{l}0.16 \\
(0.11)\end{array}$ & $\begin{array}{l}0.20 \\
(0.09)\end{array}$ & $\begin{array}{l}0.12 \\
(0.09)\end{array}$ & $\begin{array}{l}0.10 \\
(0.06)\end{array}$ & $\begin{array}{l}0.11 \\
(0.10)\end{array}$ & $\begin{array}{l}0.10 \\
(0.10)\end{array}$ & $\begin{array}{l}0.11 \\
(0.09)\end{array}$ & $\begin{array}{l}10.74 \\
(1.74)\end{array}$ & $\begin{array}{l}0.59 \\
(0.66)\end{array}$ \\
\hline$p, p^{\prime}$-DDD & $\begin{array}{l}0.09 \\
(0.06)\end{array}$ & $\begin{array}{l}0.05 \\
(0.03)\end{array}$ & $\begin{array}{l}0.11 \\
(0.09)\end{array}$ & $\begin{array}{l}0.05 \\
(0.07)\end{array}$ & $\begin{array}{l}0.06 \\
(0.08)\end{array}$ & $\begin{array}{l}0.10 \\
(0.14)\end{array}$ & $\begin{array}{l}0.06 \\
(0.05)\end{array}$ & $\begin{array}{l}0.04 \\
(0.05)\end{array}$ & $\begin{array}{l}0.04 \\
(0.06)\end{array}$ & $\begin{array}{l}0.07 \\
(0.09)\end{array}$ & $\begin{array}{l}0.42 \\
(0.40)\end{array}$ & $\begin{array}{l}0.03 \\
(0.02)\end{array}$ \\
\hline o,p'-DDD & $\begin{array}{l}0.07 \\
(0.05)\end{array}$ & $\begin{array}{l}0.05 \\
(0.03)\end{array}$ & $\begin{array}{l}0.09 \\
(0.07)\end{array}$ & $\begin{array}{l}0.06 \\
(0.09)\end{array}$ & $\begin{array}{l}0.06 \\
(0.09)\end{array}$ & $\begin{array}{l}0.07 \\
(0.08)\end{array}$ & $\begin{array}{l}0.05 \\
(0.04)\end{array}$ & $\begin{array}{l}0.03 \\
(0.04)\end{array}$ & $\begin{array}{l}0.02 \\
(0.02)\end{array}$ & $\begin{array}{l}0.03 \\
(0.02)\end{array}$ & $\begin{array}{l}0.15 \\
(0.18)\end{array}$ & $\begin{array}{l}0.02 \\
(0.01)\end{array}$ \\
\hline$\sum \mathrm{DDT}$ & $\begin{array}{l}5.42 \\
(3.77)\end{array}$ & $\begin{array}{l}1.97 \\
(1.63)\end{array}$ & $\begin{array}{l}2.60 \\
(2.29)\end{array}$ & $\begin{array}{l}2.07 \\
(2.10)\end{array}$ & $\begin{array}{l}2.52 \\
(1.34)\end{array}$ & $\begin{array}{l}2.29 \\
(1.96)\end{array}$ & $\begin{array}{l}1.11 \\
(0.78)\end{array}$ & $\begin{array}{l}1.39 \\
(1.35)\end{array}$ & $\begin{array}{l}1.54 \\
(2.68)\end{array}$ & $\begin{array}{l}1.43 \\
(1.11)\end{array}$ & $\begin{array}{l}14.28 \\
(12.91)\end{array}$ & $\begin{array}{l}1.01 \\
(0.95)\end{array}$ \\
\hline $\mathrm{HCB}$ & $\begin{array}{l}115.4 \\
(68.74)\end{array}$ & $\begin{array}{l}99.07 \\
(20.54)\end{array}$ & $\begin{array}{l}91.93 \\
(28.28)\end{array}$ & $\begin{array}{l}108.16 \\
(134.72)\end{array}$ & $\begin{array}{l}80.27 \\
(17.29)\end{array}$ & $\begin{array}{l}86.73 \\
(17.54)\end{array}$ & $\begin{array}{l}55.40 \\
(10.15)\end{array}$ & $\begin{array}{l}59.21 \\
(31.40)\end{array}$ & $\begin{array}{l}52.88 \\
(16.29)\end{array}$ & $\begin{array}{l}54.14 \\
(10.85)\end{array}$ & $\begin{array}{l}65.39 \\
(5.96)\end{array}$ & $\begin{array}{l}67.09 \\
(7.73)\end{array}$ \\
\hline
\end{tabular}

Note: Unusually high concentrations in 1994 and 2004 are in italic.

and updated in Excel spreadsheet format, with data periodically fed into AMAP and the Co-operative Programme for Monitoring and Evaluation of the Long Range Transmission of Air Pollutants in Europe (EMEP) programmes (e.g. AMAP, 2002).

\subsection{Trend analysis using Dynamic Harmonic Regression (DHR)}

DHR is a sophisticated time-series analysis tool using stochastic time variable parameters (TVPs), which can evolve over time thus allowing the tracking of changes in source strengths and types. Due to this, and the estimation method applied, quantitative confidence can be attributed to the resulting 'smooth' trend lines estimated using this tool. This modelling approach has been described in detail elsewhere (Young, 1999; Young et al., 1999; Tych et al., 2002; Becker et al., 2006, 2008). In brief, DHR identifies trend (non-linear), seasonal, cyclical and irregular (or unmodelled) components in the time-series data set which then can be used to present an overall trend and temporal evolution of seasonal components. A simpler form of the model is used here as the cyclical component is not modelled. This is described by Eq. (1).

$\mathrm{y}_{\mathrm{t}}=\mathrm{T}_{\mathrm{t}}+\mathrm{S}_{\mathrm{t}}+\mathrm{e}_{\mathrm{t}}$

where $y_{t}$ is the time series; $T_{t}$ is a longer term trend or lowfrequency, slowly changing component; $\mathrm{S}_{\mathrm{t}}$ the seasonal component and $e_{t}$ an irregular or "noise" component due to the inherent variations found in atmospheric data caused, for example, by incursions of polluted or 'clean' air masses over the sampling site.

Fortnightly (bi-weekly) concentrations were used for the time-series analysis. Missing values or outliers (deemed as $>3 *$ inter-quartile range - see Becker et al. (2008)) were replaced by a "NaN flag" (not a number) allowing DHR to interpolate across these points. The quality control procedures applied to the dataset ensure that only those weekly concentrations deemed above the method detection limits were included in the dataset (Oehme et al., 1995).

\section{Results and discussion}

Table 1 shows the arithmetic mean concentrations $\left(\mathrm{pg} \mathrm{m}^{-3}\right)$ for all the chemicals investigated (standard deviation in parentheses) for the years 1994-2005 inclusive. A simple comparison of these arithmetic means recorded in 1994 and 2005 show a decline for all compounds throughout the sampling period, which is in agreement with studies conducted in Arctic Canada and regions that are operated under the Canadian Northern Contaminants Program (Bailey, 2001; Hung et al., 2005; Su et al., 2008). The following sections compare concentrations from previous publications resulting from earlier sampling campaigns, conducted primarily at Zeppelin and Alert, and look at the seasonality displayed by each of the chemicals investigated. The longer-term trends 
are interpreted and related to changing patterns in use and source distribution.

Chlordanes - Both of the isomers (trans- and cis-) show a slight decline throughout the time series, although concentrations recorded at the beginning of the sampling campaign are not statistically different from earlier campaigns conducted in the spring of 1992 and March-December of 1993 (Oehme et al., 1995, 1996) (see Table 1). These earlier studies report average concentrations of $0.55 \pm 0.23 \mathrm{pg} \mathrm{m}^{-3}$ for trans-chlordane (TC) and $0.98 \pm 0.38 \mathrm{pg} \mathrm{m}^{-3}$ for cischlordane (CC) in 1992 (0.53 and $1.09 \mathrm{pg} \mathrm{m}^{-3}$ in 1993) (Oehme et al., 1995, 1996). The concentrations in 1992 were also found to be similar to those reported in 1984 (Oehme et al., 1995). Average concentrations of TC and CC measured at Alert were 0.32 and $0.75 \mathrm{pg} \mathrm{m}^{-3}$, respectively, for the period 2002-2003 and were similar to those observed at Zeppelin.

Both TC and CC display seasonal variations, although there are different patterns observed for the two isomers. Figure 1 presents the observed data and the DHR model fit for both TC (A) and CC (B). Strong annual signals are identified by DHR for TC, marked by distinct winter maxima and summer minima, together with a weaker 6 monthly pattern. In contrast, $\mathrm{CC}$ shows a stronger 6 monthly (bi-modal) pattern, again with winter maxima, but with two, more distinct "peaks" in spring (March-May), and September-November. These seasonal differences could be due to the preferential photodegradation of TC during the summer months, compared to CC (Oehme, 1991). This seasonality is also supported by examining the ratios of TC/CC. In 1984, the average summer ratio was $\sim 0.5$ and the average winter ratio was $\sim 1$ (Oehme, 1991). The latter winter ratio is similar to the ratio of technical chlordane, and the author attributes this to long-range transport primarily from North America, although some episodes were associated with air masses originating from southern Europe. Chlordanes were not used in central Europe (Bidleman et al., 1987) so episodes of elevated concentrations may be attributed to chlordane use in countries such as Spain or Portugal, from exchange with surface sea water, or mixing with polluted air masses over the North Atlantic. Annual average ratios of TC/CC ranged from $0.12-0.58$ in summer (June-August) and 0.59-0.88 in winter (January-March). The values from 2001 (i.e. 1.49 in summer; 1.03 in winter) are not included in these ranges as several values in this year were determined when the concentrations of either TC or CC were at or below the method detection limit, with the effect of skewing the calculated ratios. The seasonal ratios for each year are given in Table 1 and the average monthly ratios are displayed in Fig. 2 to show the pattern relating to summertime depletion (possibly reflecting enhanced photodegradation) of TC. Ratios ranging from 0.78 to 1.29 in the Canadian Arctic, just west of Ellesmere Island in February to April in 1988 (Patton et al., 1991) could be indicative of use patterns at this time. Previously TC/CC ratios reported for sampling campaigns during the same period at a number of Arctic sites were all $<1$ in 1993/1994 (Halsall et al., 1998). An increase in ratios between 1993-1997 measured at Alert with several episodes where ratios were $>1$ were attributed to sporadic fresh applications of chlordanebased pesticides (Hung et al., 2002, 2005). In more recent investigations at Alert and other Arctic locations (with the exception of Point Barrow, Alaska) all ratios have been reported to be $<1$ reflecting a 'weathered' signal, probably resulting from re-emissions from contaminated soils (Hung et al., 2005; Su et al., 2008). The higher ratios seen at Point Barrow in 2000-2003 were attributed to applications of technical heptachlor containing TC and CC, as the higher ratios coincided with higher than average heptachlor concentrations ( $\mathrm{Su}$ et al., 2008).

The long-term trends of TC and CC, as depicted by DHR, in Fig. 1 (c and d) show a decline throughout the timeseries, although these were only slight. Whilst the decline for $\mathrm{CC}$ was not consistent across the time-series, with an increasing trend observed from 2000-2002, both isomers have decreased over the $12 \mathrm{yr}$ period. Berg et al. (2004) did not observe any trend when analysing data from Zeppelin from 1993-2002, and this current study only shows a decrease of $\log 0.6 \mathrm{pg} \mathrm{m}^{-3}\left(0.25 \mathrm{pg} \mathrm{m}^{-3}\right)$ in concentrations when comparing the beginning and end of the model trend lines. Similarly, trends seen at Alert for the period 1993 to 1999 demonstrated only a slight decline (Hung et al., 2005). There are several factors which may influence the rates of decline for these two isomers. The shallow gradient of the fitted trend lines, probably reflect the fact that these chemicals are still being introduced into the atmosphere through re-volatilisation from soils (Bildeman et al., 2004, Bidleman and Leone, 2004); although re-volatilisation from ice-free Arctic Ocean surface waters into the overlying atmosphere is uncertain, due to the lack of measurements. The use of technical heptachlor which contains both TC and CC may also influence levels in the contemporary arctic atmosphere (Hung et al., 2002). The difference in degradation rates for the two isomers may also influence their relative decline. The potential of TC to be degraded through photolysis has been mentioned previously, however, this isomer is also thought to be preferentially degraded by marine biota from several trophic levels, and is more readily metabolised to oxychlordane, compared to the more stable CC isomer (Kawano et al., 1988).

DDTs - Elevated concentrations of the DDTs observed in 2004 (with the exception of $p, p^{\prime}$-DDT) are highlighted in Table 1. These were apparent from mid-June to December with $o, p^{\prime}$-DDE showing the highest concentrations, reaching a maximum of $28 \mathrm{pg} \mathrm{m}^{-3}$ in August and September, then declining to $\sim 10 \mathrm{pg} \mathrm{m}^{-3}$ in December. At Alert, high concentrations were also apparent during 2004, with one sample week (beginning $17^{\text {th }}$ May) displaying elevated concentrations of $o, p^{\prime}$-DDE $\left(30 \mathrm{pg} \mathrm{m}^{-3}\right)$ and $p, p^{\prime}$-DDE $\left(41 \mathrm{pg} \mathrm{m}^{-3}\right)$. All other DDT-related compounds were also high during this event (H. Hung, personal communication, 2008), although these elevated concentrations were not apparent at Zeppelin 
A

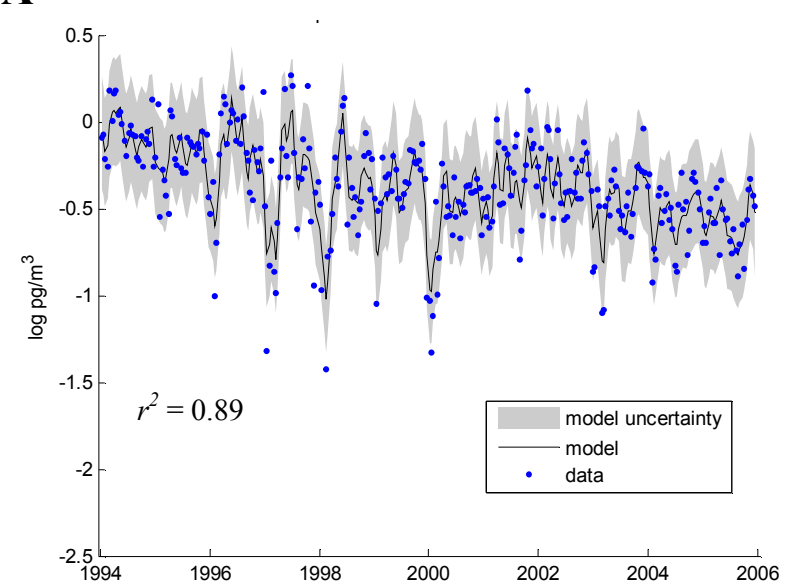

B

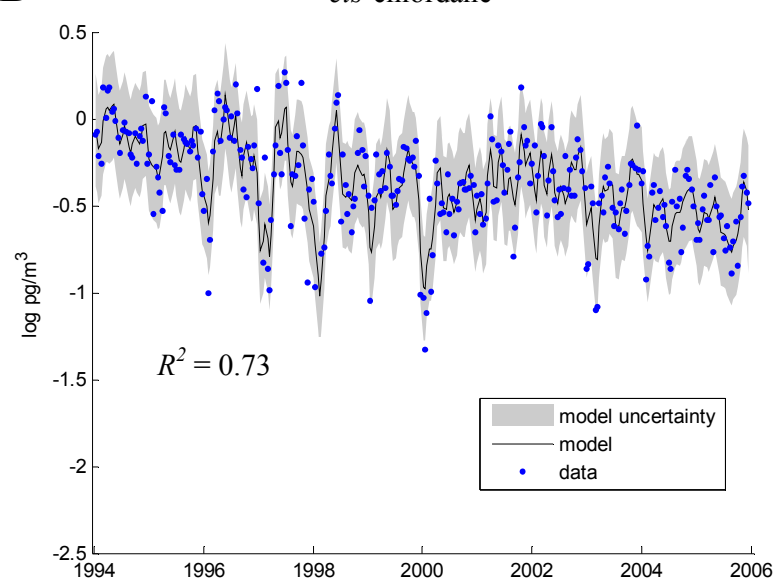

trans-chlordane

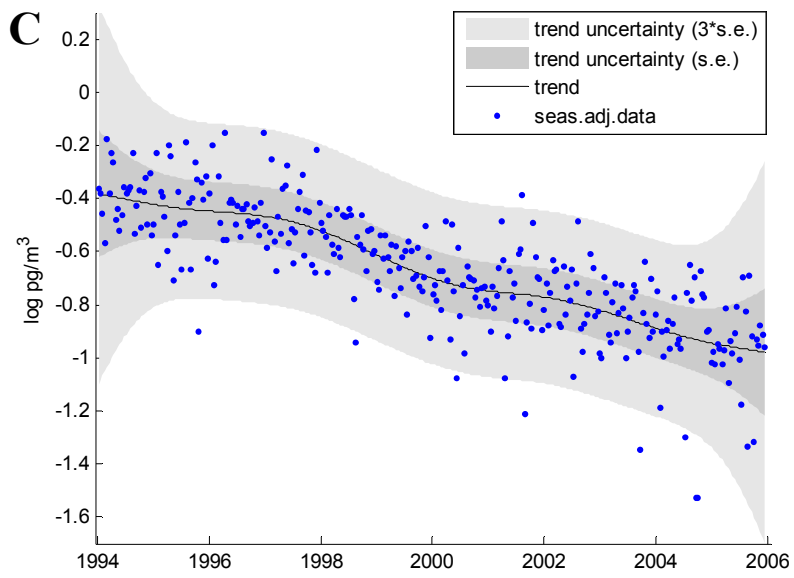

D

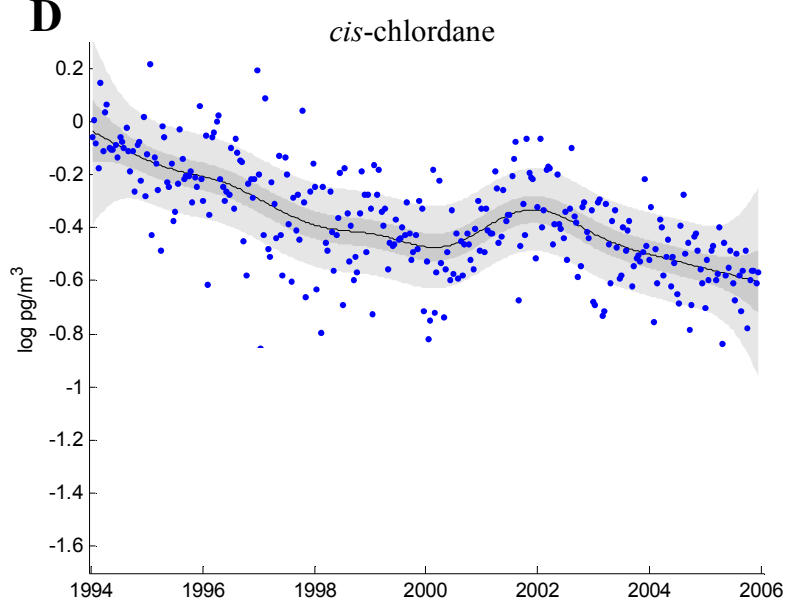

Fig. 1. Measured data and model fit for trans-chlordane (A) and cis-chlordane (B) with goodness of fit between observed data and model fit expressed by the $r^{2}$ value ( $p<0.05$ ). Seasonally adjusted data and underlying trends are provided in plots (C) (trans-chlordane) and (D) (cis-chlordane).

over the same period. Nonetheless, elevated DDT concentrations during 2004 are apparent at both the Canadian and Norwegian monitoring stations, indicating some regional source or event that lead to these high concentrations. A study by Eckhardt et al. (2007), found that extensive forest fires in sub-Arctic regions, and areas further south, were a source of previously deposited POPs to the atmosphere, including the DDTs. Atmospheric long-range transport resulted in this fire "signal;; being observed at Zeppelin, although this was 3-4 weeks later than at the monitoring stations of Barrow (Alaska) and Summit (Greenland) due to the greater distance involved. Back trajectories carried out for 24-26 July 2004 (when high values of aerosol light absorption coefficients were measured at Zeppelin) showed air mass origins within the boreal forest region, with air bypassing Alert, but affecting Zeppelin (Eckhardt et al., 2007). This is a possible ex- planation of the elevated values observed at Zeppelin during this period.

The seasonality and longer term trend of DDTs identified by DHR do not appear to be affected by 'episodes' that occurred in 2004, with the exception of $o, p^{\prime}$-DDE. For this reason, the trend analysis was conducted using the entire timeseries for all the DDTs, except $o, p^{\prime}$-DDE, which was investigated from 1994-2003 only.

The seasonality displayed by DDTs is broadly characterised by winter maxima and summer minima, although this is less apparent for the DDDs. This was identified by DHR, with the most pronounced seasonality observed for the DDEs (especially $o, p^{\prime}$-DDE). These seasonal patterns are shown in Fig. 3, which gives the observed data and DHR model fit for each of the compounds. These patterns are in agreement with previous studies that have examined Canadian air datasets, but over a much shorter time period (i.e. several years of 


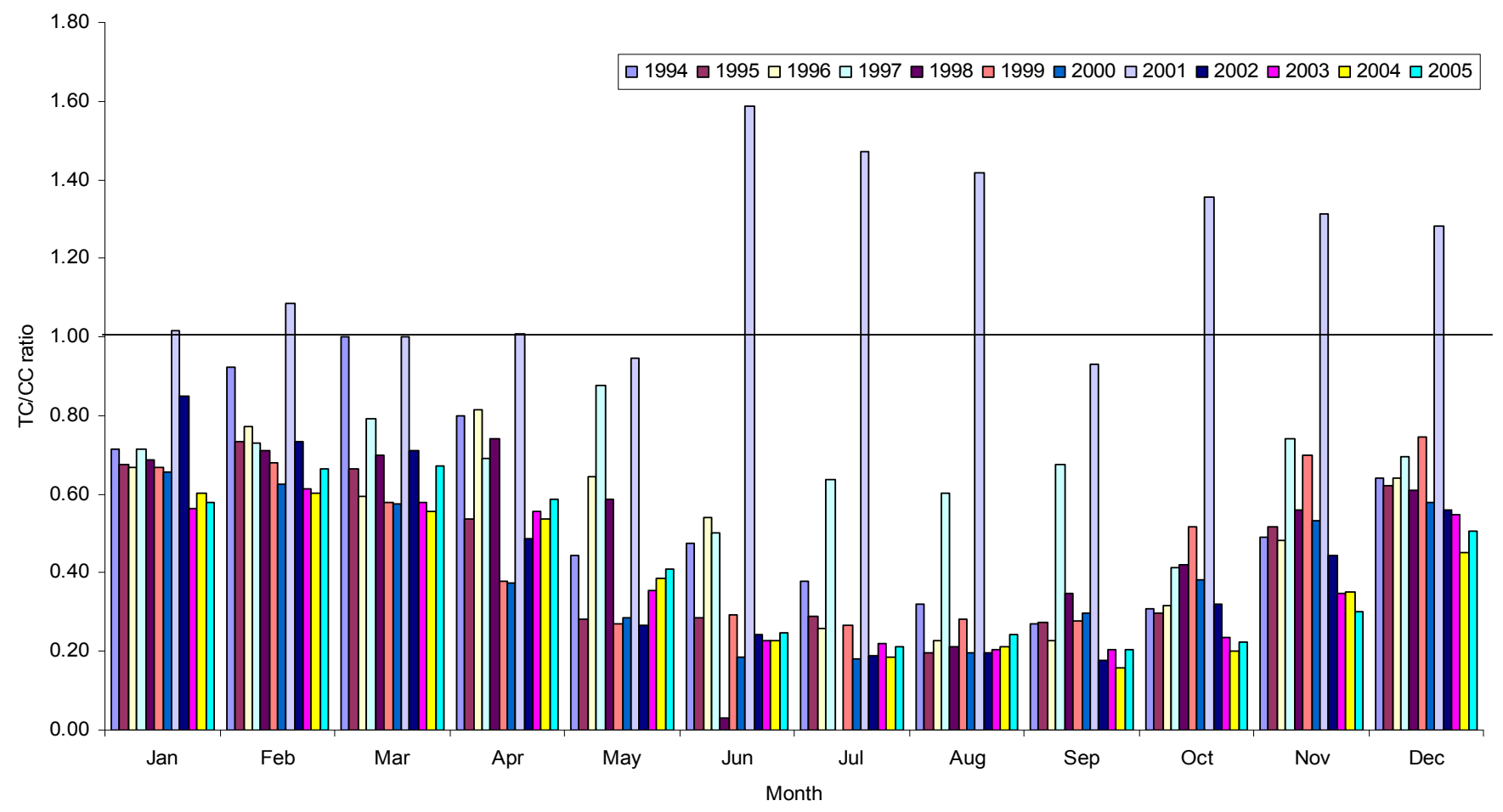

Fig. 2. Average monthly TC/CC ratios at Zeppelin 1994-2005.

systematic data) (Halsall et al., 1998; Bailey et al., 2000; Hung et al., 2002).

The time series of DDT/DDE+DDD and $o, p^{\prime}-\mathrm{DDT} / p, p^{\prime}-$ DDT ratios are presented in Fig. 4 and provide a useful insight into the seasonal composition of the DDTs. The sum degradation products from DDT (i.e. $o, p^{\prime}-$ and $p, p^{\prime}-$ isomers of DDE and DDD, compared to both isomers of DDT) were included here, as use of $p, p^{\prime}$-DDT/ $p, p^{\prime}$-DDE ratios alone may be misleading due to the degradation of $p, p^{\prime}$-Cl-DDT (contained in dicofol) to $p, p^{\prime}$-DDE (Qiu et al., 2005). Figure 4 illustrates $p, p^{\prime}$-DDT dominating during the Arctic summer and $p, p^{\prime}$-DDE dominating during winter, a pattern that was also observed by Bailey et al. (2000) and Berg et al. (2004), who both attributed the higher winter values of $p, p^{\prime}$-DDE to long range transport from Asia. Another reason for the winter increase in $p, p-\mathrm{DDE}$ (the metabolite of $p, p^{\prime}$-DDT) could be due to transport with particles (aeolian dusts), coinciding with elevated aerosol levels during the Arctic Haze period (Halsall et al., 1998; Hung et al., 2002). Furthermore, Su et al. (2006) have recognised that DDTs could be more susceptible to precipitation scavenging during the warmer arctic summer.

Figure 5 presents the trends identified by DHR for the major DDT compounds. A declining trend was only apparent for $p, p^{\prime}$-DDT across the time series. Although a significant decrease in concentrations is evident at the beginning of the time series for $o, p^{\prime}$-DDE, this is thought to be due to the high values recorded in 1994 ( $\sim 7$ times greater than those in previous (Oehme et al., 1996) and subsequent years, Table 1), rather than a significant decline at this time. It is difficult to explain these high values which may arise due to a variety of factors, including: episodes associated with boreal forest fires (discussed earlier); other phenomena such as a pronounced Arctic Haze season; or the fresh use of technical DDT/dicofol and subsequent LRT. The only DDT isomer, which shows any consistent decline throughout the time series, is $p, p^{\prime}$-DDT (Fig. 5). These results are in agreement with other studies investigating DDTs, with $p, p^{\prime}-$ DDE showing the lowest variation in concentrations across the time series. This would support the theory that $p, p^{\prime}-\mathrm{Cl}-$ DDT, present in dicofol, may also be a source of $p, p^{\prime}$-DDE and helping to maintain levels in the atmosphere.

Dicofol is produced and used in southern Europe, India, China, Israel and Brazil. Spain produces $\sim 1500 \mathrm{t}$ per year (processing is conducted in Italy), and use was reported to be 100-150t in 2000 (van de Plassche et al. 2003). The amount of DDT related compounds present in dicofol is heavily regulated in most countries, with a maximum of $0.1 \%$ DDT impurity permitted. However, a content of $3.5 \%$ DDTs has been reported in dicofol produced in India (van de Plassche et al., 2003). China has been a major producer of technical DDT and dicofol, with $>85 \%$ of the global technical DDT production occurring here, which amounted to $\sim 97000 \mathrm{t}$ between 1988 and 2002. Over half of this amount $(\sim 54000 \mathrm{t})$ was used to manufacture dicofol $(\sim 40000 \mathrm{t})$, which contains average DDT impurities of $244 \pm 73 \mathrm{~g} \mathrm{~kg}^{-1}$ 

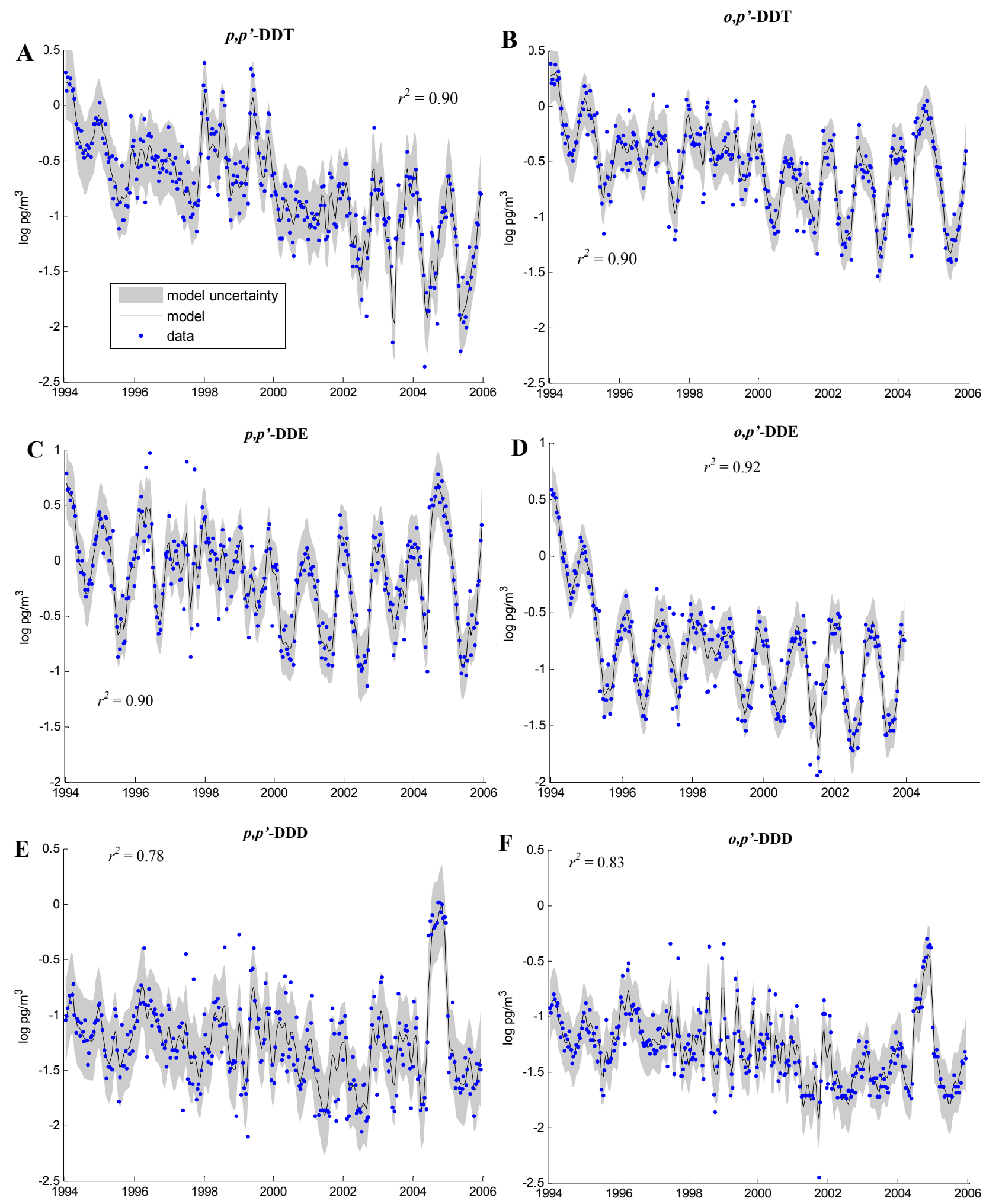

Fig. 3. Measured data and model fit for $p, p^{\prime}$-DDT (A); $o, p^{\prime}$-DDT (B); $p, p^{\prime}$-DDE (C); $o, p^{\prime}$-DDE (D); $p, p^{\prime}$-DDD (E) and $o, p^{\prime}$-DDD (F). Goodness of fit is provided in each case by the $r^{2}$ value $(p<0.05)$. 

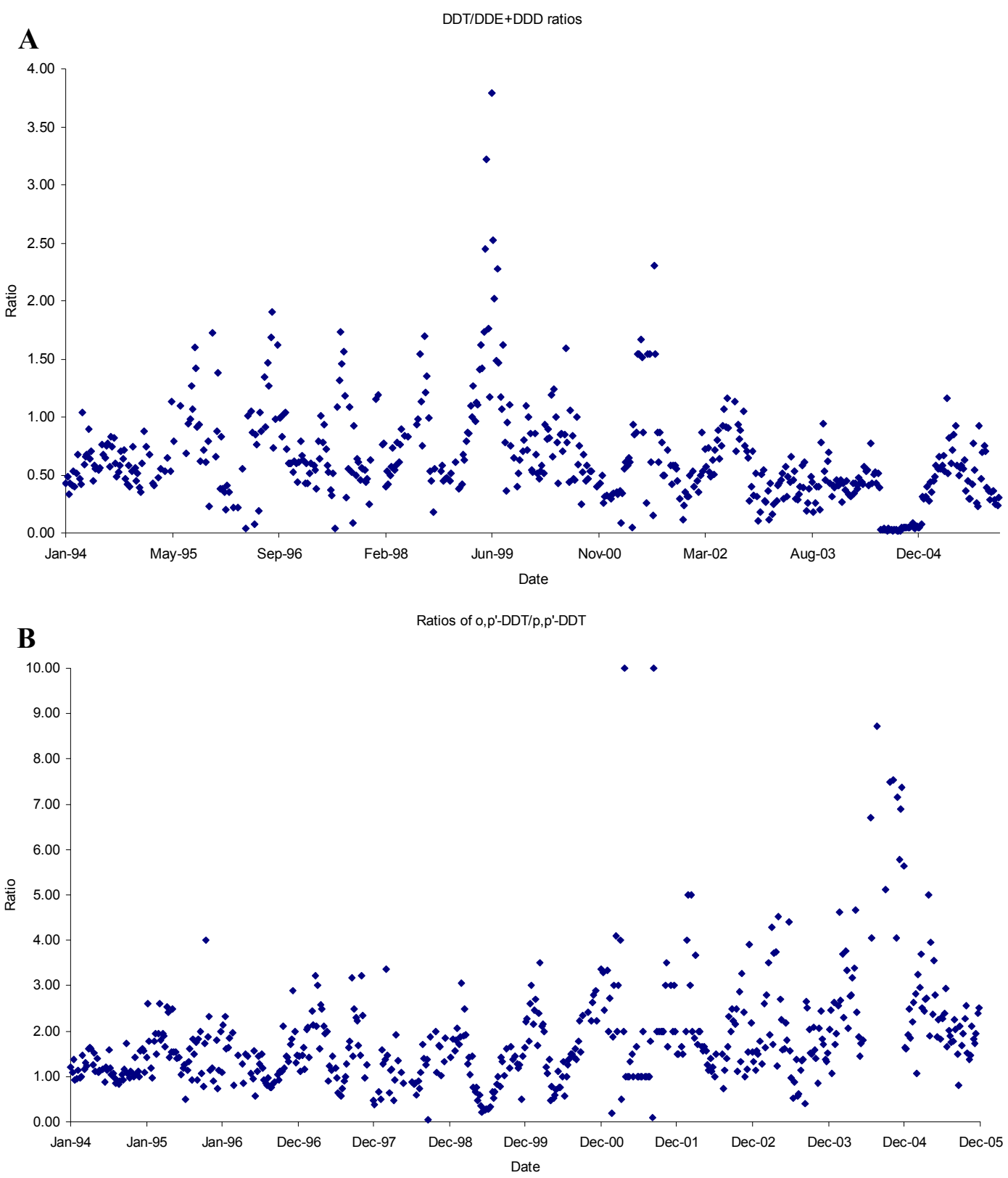

Fig. 4. Ratios of DDT/DDE+DDD (A) to illustrate the age of the DDT signal, and $o, p^{\prime}$-DDT/ $p, p^{\prime}$-DDT (B) to indicate whether sources are from Dicofol or Technical-DDT.

dicofol (Qiu et al., 2005). This quantity of impurity is much greater than any reported by other countries producing this chemical (India, Brazil, Spain and Israel), although information is not always readily available (van de Plassche et al. 2003). The predominant DDT impurity found in dicofol is $o, p^{\prime}$-DDT $\left(114 \pm 45 \mathrm{~g} \mathrm{~kg}^{-1}\right.$ dicofol), followed by $p, p^{\prime}$-ClDDT $\left(69 \pm 40 \mathrm{~g} \mathrm{~kg}^{-1}\right.$ dicofol). A recent study conducted in the Central Himalayas, China, found that DDT was present in ice cores for the period 1990-2005, whereas DDE was not found (Wang et al., 2008). The authors conclude that there has been on-going use of Technical DDT in India after the ban was put in place. It could, however, also be from accidental release during the production of dicofol.

Hexachlorobenzene (HCB) - Concentrations of HCB measured at Zeppelin in the spring of 1992, and MarchDecember 1993 ranged from $121-372 \mathrm{pg} \mathrm{m}^{-3}$, and 23 $312 \mathrm{pg} \mathrm{m}^{-3}$, respectively (Oehme et al., 1995, 1996). The concentrations observed in 1992 are similar to those reported in 1984 (Oehme et al., 1995), which would reflect the on-going production and use of this chemical during this period (Bailey, 2001). Spatial variability across the Arctic is slight with the annual means at Zeppelin comparable to 

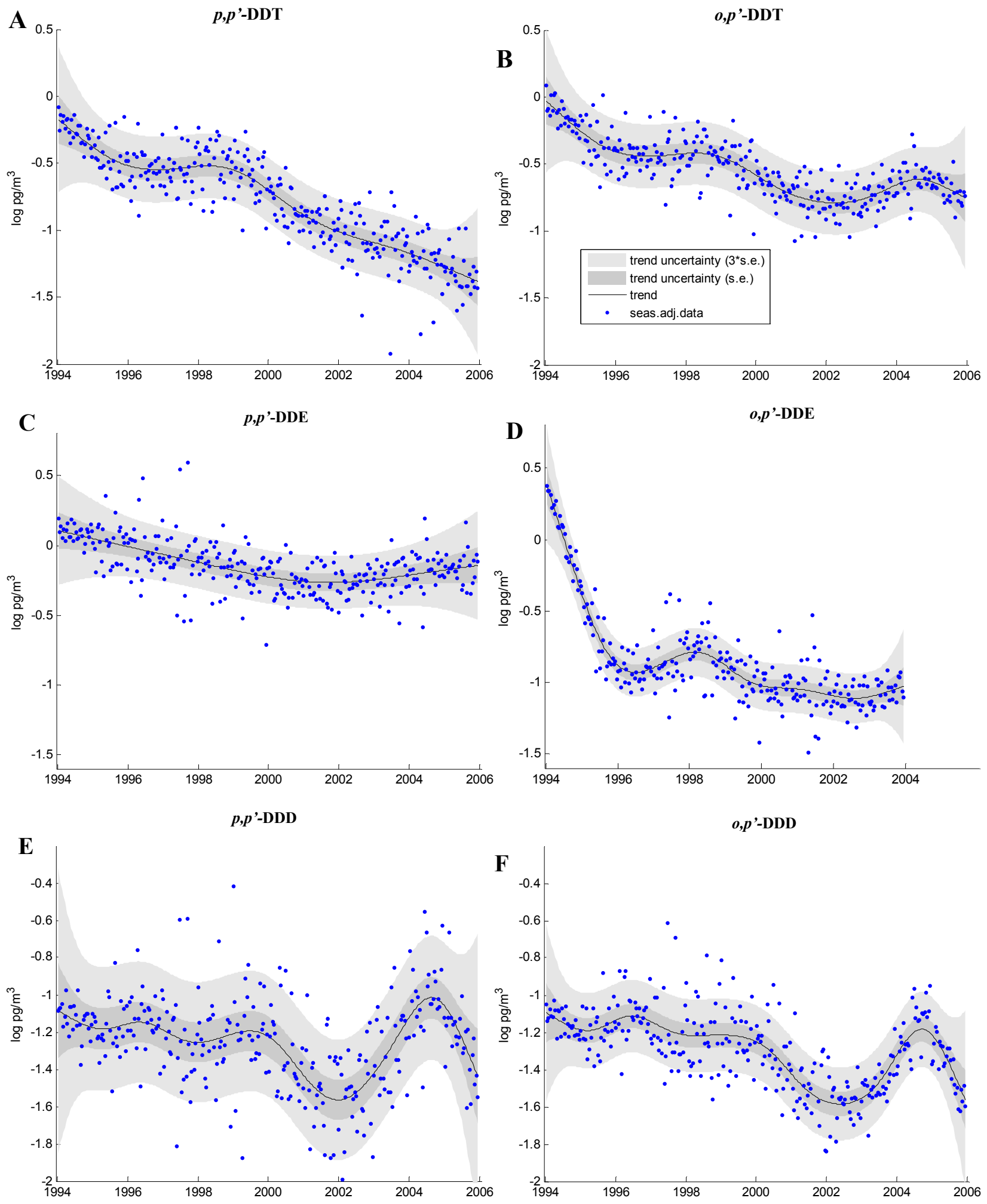

Fig. 5. Seasonally adjusted data and underlying trends for $p, p^{\prime}$-DDT (A); $o, p^{\prime}$-DDT (B); $p, p^{\prime}$-DDE (C); $o, p^{\prime}$-DDE (D); $p, p^{\prime}$-DDD (E) and $o, p^{\prime}$-DDD (F). (o, $p^{\prime}$-DDE plot excludes 2004-2005 data). 


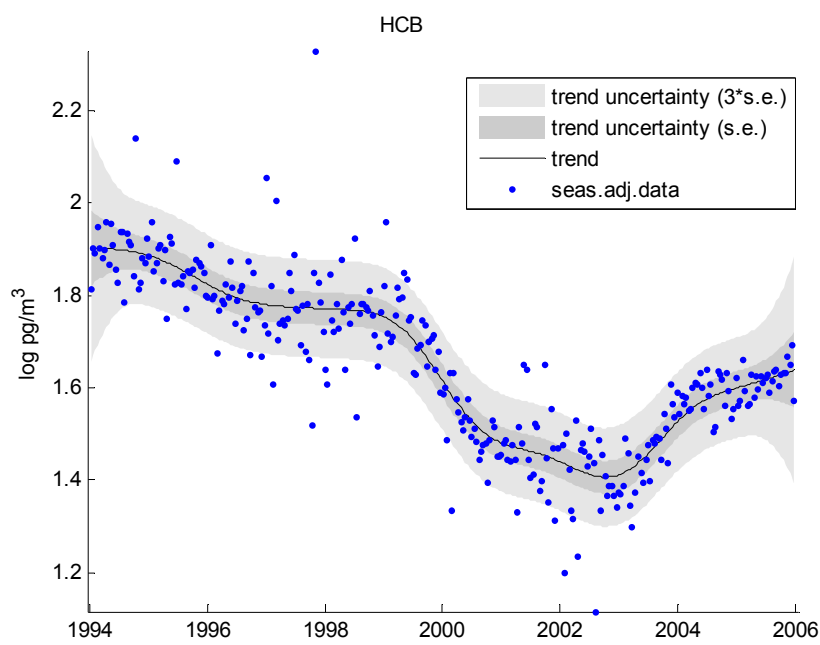

Fig. 6. Seasonally adjusted data and underlying trend for HCB.

those measured at Alert, although several spurious values $\left(>500 \mathrm{pg} \mathrm{m}^{-3}\right.$ ) were measured at Zeppelin during October 1997. A passive sampling campaign carried out from August 2000 to August 2001 at Zeppelin by Shen et al. (2005) reported a concentration of $71 \mathrm{pg} \mathrm{m}^{-3}$, which is akin to the annual averages at Zeppelin for these years. HCB is relatively volatile compared to the other OC pesticides examined in this study and breakthrough of this chemical through the sampling media is a significant problem, which may lead to an underestimation of the true atmospheric concentration, particularly during the warmer summer months (e.g. Halsall et al., 1998). Breakthrough of HCB in the sampling media averaged $27 \%$ of all air samples taken at Alert (Hung et al., 2005), with a similar range of 20-30\% reported at Zeppelin (Oehme et al., 1995). Meaningful seasonal patterns could not be distinguished by DHR and therefore, only the longer term trend is discussed here.

An investigation into long-term trends at Zeppelin revealed a $47 \%$ reduction over the period from 1994-2002 (Berg et al., 2004). This is in close agreement with the reduction seen in this study over the same time period, (46\% reduction in arithmetic annual means, 1994-2002). Figure 6 displays the underlying trend for $\mathrm{HCB}$ at Zeppelin using DHR. Interestingly, after an initial decrease, there is an apparent upturn in concentrations for the last three years of the time-series (2003-2005). At present it is unclear why this change in pattern occurs. Re-volatilisation or re-cycling of HCB between environmental compartments would result in a slowing of any decline (like the other OCs) following usereduction of this chemical, but is unlikely to cause an increase in air concentrations. Although no information on potential sources from developing countries has been available, recent investigations into these compounds have found revolatilisation from previously contaminated soils and vegetation to be a significant influence on atmospheric concentra- tions (Bailey, 2001; Barber et al., 2005). However, it is possible that the trend observed here simply reflects a "bottomingout' of the year-on-year decrease observed throughout the 1990s and early 2000s, although a continuation of the timeseries will be needed to confirm this. Unlike the isomers of hexachlorocyclohexane $(\mathrm{HCH})$ reported by Becker et al. (2008) from the same database, there was no relationship observed between HCB concentrations and either the +ve or - ve phases of the North Atlantic or Arctic Oscillations. HCB has been shown to be undergoing net deposition to the Arctic Ocean for the period 2000-2003 (Su et al., 2006). Since surface ocean water surrounding Svalbard is largely ice-free for most of the year, then the "upturn" in the atmospheric trend evident in the last few years of the Zeppelin dataset, may simply reflect equilibrium between air and marine surfaces. The recent increase in ice-free months in the ocean surrounding Svalbard due to changes in climate (Kallenborn et al., 2007), could affect the environmental cycling of chemicals such as HCB, and a further decline in air concentrations may only be realised by many more years of sampling. Since a switch from net deposition to net volatilisation alone may not explain the increase in HCB concentrations, it is plausible that the presence of HCB in currently used pesticides as an impurity is also having an impact. The fungicides, chlorothalonil and quintozene, and the arachnicide, tetradifon, have been shown to contain HCB as impurities (Gouin et al., 2008). In the UK, for example, the use of tetradifon has declined over the last decade, whereas chlorothalonil on the other hand, has been applied much more widely over the 2004-2006 period. According to the pesticide usage statistics database (http://pusstats.csl.gov.uk/), the total mass applied of chlorothalonil (in Great Britain) was estimated to be $\sim 500 \mathrm{t}$ in 2003 , compared to $\sim 1500 \mathrm{t}$ in 2006 , a 3-fold increase. If similar increases in use are apparent in other European countries, then this could provide a significant source of "new" HCB to the environment. The quantity of HCB contained within chlorothalonil ranges from $0.1-0.3 \mathrm{~g} \mathrm{~kg}^{-1}$ (EPA, 2008). Furthermore, Gouin et al. (2008) found that levels of HCB in air measured in a central valley in Costa Rica were from the historical use of HCB and the ongoing use of fungicides such as chlorothalonil which is applied in banana plantations (Chaves et al., 2007).

\section{Conclusions}

An examination of arithmetic means of the OC pesticides measured in the Norwegian Arctic over the period 19942005, reveals a slight decline in concentrations, which is in agreement with the long-term datasets from Alert in the Canadian Arctic. The long-term trends, however, show that the rate of decline in concentrations is slow, probably reflecting ongoing re-emission of these compounds from soil and other secondary sources. Dicofol used in Asia, South America, and southern Europe, together with on-going use of 
Technical DDT, may also be hindering the decline of some of the DDTs particularly $p, p^{\prime}$-DDE, although further evidence is needed to support this. The trends observed for chlordane isomers imply that sources affecting the Arctic are now secondary in nature. On the other hand, the initial decline in HCB concentrations over the 1990s and early 2000s is offset by an increasing trend from 2003 onwards. The increased use of chlorothalonil and continued use of other pesticides containing HCB as an impurity, combined with environmental factors that affect secondary "reservoirs", such as the reduction in sea-ice cover, could be influencing contemporary levels of this chemical in the Arctic atmosphere.

DHR, in combination with these datasets, is proving to be a highly valuable tool for identifying long-term trends in contaminant data in the remote Arctic atmosphere.

Acknowledgements. SB was funded under NERC studentship NER/S/A/2004/12159. The authors would like to thank Hayley Hung of Environment Canada and Peter Coleman of NETCEN, UK for useful discussions.

Edited by: J. W. Bottenheim and T. Bond

\section{References}

AMAP, Arctic Monitoring and Assessment Programme: Arctic Pollution 2002: Persistent Organic Pollutants, Heavy Metals, Radioactivity, Human Health, Changing Pathways, AMAP, Oslo, Norway, 2002.

Bailey, R., Barrie, L. A., Halsall, C. J., Fellin, P., and Muir, D. C. G.L Atmospheric organochlorine pesticides in the western Canadian Arctic: Evidence of transpacific transport, J. Geophys. Res., 105, 11805-11811, 2000.

Bailey, R. E.: Global hexachlorobenzene emissions, Chemosphere, 43, 167-182, 2001.

Barber, J. L., Sweetman, A. J., van Wijk, D., and Jones, K. C.: Hexachlorobenzene in the global environment: Emissions, levels, distribution, trends and processes, Sci. Total Environ., 349, 1-44, 2005.

Becker, S., Halsall, C. J., Tych, W., Hung, H., Attewell, S., Blanchard P., Li, H., Fellin, P., Stern, G., Billeck, B., and Friesen, S.: Resolving the long-term trends of polycyclic aromatic hydrocarbons in the Canadian Arctic Atmosphere, Environ. Sci. Technol., 40, 3217-3222, 2006.

Becker, S., Halsall, C. J., Tych, W., Kallenborn, R., Su, Y., and Hung, H.: Long-term trends in atmospheric concentrations of $\alpha$ and $\gamma-\mathrm{HCH}$ in the Arctic provide insight into the effects of legislation and climatic fluctuations on contaminant levels, Atmos. Environ., 42, 8225-8233, 2008.

Berg, T., Kallenborn, R., and Stein, M.: Temporal trends in atmospheric heavy metal and organochlorine concentrations at Zeppelin, Svalbard. Arctic, Antarct. Alp. Res., 36, 284-291, 2004.

Bidleman, T. F., Widekvist, U., Jansson, B., and Söderlund, R.: Organochlorine pesticides and PCBs in the atmosphere of Southern Sweden, Atmos. Environ. 21, 641-654, 1987.

Bidleman, T. F., Jantunen, L. M. M., Helm, P. A., BrorströmLunden, E., and Juntto, S.: Chlordane Enantiomers and Temporal
Trends of Chlordane Isomers in Arctic Air, Environ. Sci. Technol., 36, 539-544, 2002.

Bidleman, T. F., Wong, F., Backe, C., Södergren, A., BrorströmLundén, E., Helm, P. A., and Stern, G. A.: Chiral signatures of chlordanes indicate changing sources to the atmosphere over the past 30 years. Atmos. Environ., 38, 5963-5970, 2004.

Bidleman, T. F. and Leone, A. D.: Soil-air exchange of organochlorine pesticides in the Southern United States, Environ. Pollut., 128, 49-57, 2004.

Chaves, A., Shea, D., and Cope, W. G.: Environmental fate of chlorothalonil in a Costa Rican banana plantation, Chemosphere, 69, 1166-1174, 2007.

Connor, M. S., Davis, J. A., Leatherbarrow, J., Greenfield, B. K., Gunther, A., Hardin, D., Murnley, T., Oram, J. J., and Werme, C.: The slow recovery of San Francisco Bay from the legacy of organochlorine pesticides, Environ. Res., 105, 87-100, 2006.

Dougherty, C. P., Holtz, S. H., Reinert, J. C., Panyacosit, L., Axelrad, D. A. and Woodruff, T. J.: Dietary exposures to food contaminants across the United States. Environmental Research A 84, 170-185, 2000.

Eckhardt, S., Breivik, K., Manø, S., and Stohl, A.: Record high peaks in PCB concentrations in the Arctic atmosphere due to long-range transport of biomass burning emissions, Atmos. Chem. Phys., 7, 4527-4536, doi:10.5194/acp-7-4527-2007, 2007.

Gouin, T., Wania, F., Ruepert, C., and Castillo, L. E.: Field testing passive air samplers for current use pesticides in a tropical environment, Environ. Sci. Technol., 42, 6625-6630, 2008.

Halsall, C. J., Bailey, R., Stern, G. A., Barrie, L. A., Fellin, P., Muir, D. G. C., Rosenberg, B., Rovinsky, F. Ya., Kononov, E. Ya., and Pastukhov, B.: Multi-year observations of organohalogen pesticides in the Arctic atmosphere, Environ. Pollut., 102, 51-62, 1998.

Hung, H., Halsall, C. J., Blanchard, P., Li, H. H., Fellin, P., Stern, G., and Rosenberg, B.: Temporal trends of organochlorine pesticides in the Canadian Arctic Atmosphere, Environ. Sci. Technol. 36, 862-868, 2002.

Hung, H., Blanchard, P., Halsall, C. J., Bidleman, T. F., Stern, G. A., Fellin, P., Muir, D. G. C., Barrie, L. A., Jantunen, L. M., Helm, P. A., Ma, J., and Konoplev, A.: Temporal and spatial variabilities of atmospheric polychlorinated biphenyls (PCBs), organochlorine (OC) pesticides and polycyclic aromatic hydrocarbons (PAHs) in the Canadian Arctic: Results from a decade of monitoring. Sci. Total Environ., 342, 119-144, 2005.

Jantunen, L. M. M., Bidleman, T. F., Harner, T., and Parkhurst, W. J.: Toxaphene, Chlordane, and other organochlorine pesticides in Alabama air, Environ. Sci. Technol., 34, 5097-5105, 2000.

Kallenborn, R., Christensen, G., Evenset, A., Schlabach, M., and Stohl, A.: Atmospheric transport of persistent organic pollutants (POPs) to Bjørnøya (Bear island), J. Environ. Monitor., 9, 10821091, 2007.

Kawano, M., Inoue, T., Wada, T., Hidaka, H., and Tatsukawa, R.: Bioconcentration and residue patterns of chlordane compounds in marine animals: invertebrates, fish, mammals and seabirds, Environ. Sci. Technol., 22, 792-797, 1988.

Li, J., Zhang, G., Qi, S., Li, X., and Peng, X.: Concentrations, enantiomeric compositions and sources of $\mathrm{HCH}$, DDT and chlordane in soils from the Pearl River Delta, South China. Sci. Total Environ., 372, 215-224, 2006. 
Li, J., Zhang, G., Guo, L., Xu, W., Li, W., Lee, C. S. L., Ding, A., and Wang, T.: Organochlorine pesticides in the atmosphere of Guangzhou and Hong Kong: Regional sources and long-range atmospheric transport, Atmos. Environ., 41, 3889-3903, 2007.

Oehme, M.: Further evidence for long range air transport of polychlorinated aromatics and pesticides from North America and Eurasia to the Arctic, Ambio, 20, 293-297, 1991.

Oehme, M., Haugen, J.-E., and Schlabach, M.: Ambient air levels of persistent organochlorines in spring 1992 at Spitsbergen and the Norwegian mainland: comparison with 1984 results and quality control measures, Sci. Total Environ., 160-161, 139-152, 1995.

Oehme, M., Haugen, J.-E., and Schlabach, M.: Seasonal Changes and Relations between Levels of Organochlorines in Arctic Ambient Air: First Results of an All-Year-Round Monitoring Program at Ny-Ålesund, Svalbard, Norway, Environ. Sci. Technol. 30, 2294-2304, 1996.

PAN (Pesticide Action Network). Active Ingredient Fact Sheets: Dicofol. http://www.pan-uk.org/pestnews/Actives/dicofol.htm, last access: April 2012

Patton, G. W., Walla, M. D., Bidleman, T. F., and Barrie, L. A.: Polycyclic Aromatic and Organochlorine Compounds in the Atmosphere of Northern Ellesmere Island, Canada, J. Geophys. Res., 96, 10867-10877, 1991.

Pesticide Usage Survey (PUS). The Food \& Environment Research Agency, UK (formerly the Central Science Laboratory, CSL), http://pusstats.csl.gov.uk, last access: April 2012.

Qiu, X., Zhu, T., Yao, B., Hu, J., and Hu, S.: Contribution of Dicofol to the current DDT pollution in China, Environ. Sci. Technol. 39, 4385-4390, 2005.

Shen, L., Wania, F., Lei, Y. D., Teixeira, C., Muir, D. C. G., and Bidleman, T. F.: Atmospheric Distribution and Long-Range Transport Behaviour of organochlorine pesticides in North America, Environ. Sci. Technol. 39, 409-420, 2005.

Shigenaka, G.: Chlordane in the marine environment of the United States: review and results from the National Status and Trends Programme. Technical Memorandum NOS OMA 55, NOAA, Seattle, WA, USA, 1990.

Su, Y., Hung, H., Blanchard, P., Patton, G. W., Kallenborn, R., Konoplev, A., Fellin, P., Li, H., Geen, C., Stern, G., Rosenberg, B., and Barrie, L. A.: Spatial and seasonal variations of hexachlorocyclohexanes (HCHs) and Hexachlorobenzene (HCB) in the Arctic Atmosphere, Environ. Sci. Technol. 40, 6601-6607, 2006.

Su, Y., Hung, H., Blanchard, P., Patton, G. W., Kallenborn, R., Konoplev, A., Fellin, P., Li, H., Geen, C., Stern, G., Rosenberg, G., and Barrie, L. A.: A circumpolar perspective of atmospheric organochlorine pesticides (OCPs): Results from six arctic monitoring stations in 2000-2003. Atmos. Environ., doi:10.1016/j.atmosenv.2008.01.054, 2008.
Tych, W., Pedegral, D. J., Young, P. C. and Davies, J.: An unobserved component model for multi-rate forecasting of telephone call demand: the design of a forecasting support system, Int. J. Forecast., 18, 673-695, 2002.

UNECE Protocol to the 1979 convention on long range transboundary air pollution on persistent organic pollutants and executive body decision 1998/2 on information to be submitted and the procedure for adding substances to annex I, II or III to the protocol on persistent organic pollutants, ECE/EB.AIR/60, United Nations, New York and Geneva, 1998.

US EPA: Office for Prevention, Pesticides \& Toxic Substances (OPPTS), Re-registration Eligibility Decision (RED): Chlorothalonil, http://www.epa.gov/oppsrrd1/REDs/0097red. pdf, last accessed: April 2012

Van de Plassche, E. J., Schwegler, M., Rasenberg, M. and Schouten, G.: DDT in Dicofol, UN-ECE report, http://www.unece.org/fileadmin/DAM/env/lrtap/TaskForce/ popsxg/2000-2003/ddt_in_dicofol.pdf, Accessed: April 2012, 2003.

Van Oostdam, J., Donaldson, S. G., Feeley, M., Arnold, D., Ayotte, P., Bondy, G., Chan, L., Dewailly, É., Furgal, C. M., Kuhnlein, H., Loring, E., Muckle, G., Myles, E., Receveur, O., Tracy, B., Gill, U., and Kalhok, S.: Human health implications of environmental contaminants in Arctic Canada: A review. Sci. Total Environ., 351-352, 165-246, 2005.

Wang, X. P., Xu, B. Q., Kang, S. C., Cong, Z. Y., and Yao, T. D.: The historical residue trends of DDT, Hexachlorocyclohexanes and polycyclic aromatic hydrocarbons in an ice core from Mt. Everest, central Himalayas, China, Atmos. Environ., 42, 66996709, 2008.

Young, P., Pedegral, D. J., and Tych, W.: Dynamic Harmonic Regression, J. Forecast., 18, 369-394, 1999.

Young, P. C.: Nonstationary time series analysis and forecasting, Prog. Environ. Sci., 1, 3-48, 1999.

Xu, D., Deng, L., Chai, Z., and Mao, X.: Organohalogenated compounds in pine needles from Beijing City, China. Chemosphere, 57, 1343-1353, 2004.

Yang, X., Wang, S., Bian, Y., Chen, F., Yu, G., Gu, C., and Jiang, X.: Dicofol application resulted in high DDTs residue in cotton fields from northern Jiangsu province, China, J. Haz. Mat., 150, 92-98, 2007.

Zhang, G., Parker, A., House, A., Mai, B., Li, X., Kang, Y., and Wang, Z. Sedimentary records of DDT and HCH in the Pearl River Delta, South China, Environ. Sci. Technol., 36, 3671-3677, 2002. 